\title{
A SIMPLIFIED PROCEDURE FOR THE EVALUATION OF THE SEISMIC PERFORMANCE OF BRIDGE PIERS ON CAISSON FOUNDATIONS
}

\author{
D. Gaudio ${ }^{1}$ and S. Rampello ${ }^{2}$ \\ ${ }^{1}$ University of Cambridge, UK (formerly Sapienza University of Rome, Italy) \\ Trumpington Street, Cambridge CB21PZ, UK \\ e-mail: dg564@cam.ac.uk \\ ${ }^{2}$ Sapienza University of Rome \\ Via Eudossiana 18, 00197, Rome, Italy \\ sebastiano.rampello@uniroma1.it
}

\begin{abstract}
In this paper, a simplified procedure for the evaluation of the seismic performance of bridge piers founded on caissons subjected to strong ground motions is outlined. To this end, the upper-bound semi-empirical relationships proposed in [1] are considered for the estimation of the seismic performance, expressed in terms of the maximum and permanent values of the deck drift ratio attained during and at the end of the seismic event. These drifts were related to the period ratio $T_{\mathrm{eq}} / T_{0}$ between the fundamental periods of the deck-pier-caisson-soil system and of the soil column in free-field conditions. The deck drift and the period ratios were extracted from the results of an extensive parametric study, where 14 different systems were subjected to 6 real high-intensity seismic records. In the parametric study, $3 D$ dynamic analyses were performed with the Finite Element Method in the time domain, in terms of effective stresses but assuming undrained conditions and adopting an elastic-plastic constitutive model to reproduce the irreversible soil behaviour under cyclic loading. As $3 D$ dynamic numerical analyses are not expected to become an every-day design tool, the period ratios $T_{\mathrm{eq}} / T_{0}$ are evaluated through empirical and analytical relationships available in the literature as well and then compared with the ratios obtained from the parametric study, to assess the possibility of using simplified relationships while still getting a reliable estimate of the deck drift ratio. It is shown that these relationships can be profitably adopted provided that a fair estimate of the equivalent shear wave velocity, depending on the intensity of the seismic inputs, is used.
\end{abstract}

Keywords: Caisson foundations, Seismic performance, Period ratio, Upper-bound empirical relationships, 3D numerical analyses, Dynamic soil-structure interaction. 


\section{INTRODUCTION}

The seismic performance of bridge piers on cylindrical caisson foundations depends on several factors, namely the geometric and mechanical properties of the superstructure, the foundations and the volume of soil deposit affected by the presence of the structure as well as the characteristics of the seismic event, that is its intensity, duration and frequency content. Complexity of the problem requires, in principle, 3D coupled non-linear dynamic analyses performed in the time domain, where the entire deck-pier-caisson-soil deposit is modelled and its elastic-plastic behaviour under cyclic loading is described through advanced constitutive models. However, this approach is too much time-consuming and therefore it is typically not adopted for design purposes, as several analyses are generally required to reproduce different seismic records derived to match a site-specific earthquake spectrum. Indeed, a few non-linear dynamic analyses are available in the literature regarding the seismic performance of the systems at hand, they referring either to specific cases $[2,3]$ or to parametric studies where soil behaviour is described using a simple elastic-perfectly plastic constitutive model in terms of total stresses, that is assimilating the soil to a mono-phase medium $[4,5]$.

Recently, Gaudio and Rampello [1] provided easy-to-use empirical relationships linking the seismic performance of bridge piers founded on cylindrical caisson foundations to the period ratio $T_{\text {eq }} / T_{0}$, where $T_{\text {eq }}$ is the fundamental period of the entire (compliant base) deck-piercaisson-soil system and $T_{0}$ is the fundamental period of the $1 \mathrm{D}$ soil column under free-field conditions. These relationships were obtained from the results of an extensive parametric study where several deck-pier-caisson-soil systems were subjected to strong seismic motions, suitably selected to promote the activation of irreversible strains in the soil deposit. 3D dynamic analyses were performed in the time domain with the Finite Element Method, assuming an undrained response of foundation soils but describing soil behavior in terms of effective stresses, using an elastic-plastic strain hardening constitutive model.

In the framework of the performance-based design, the seismic performance of the system was expressed in terms of the maximum and permanent values of the deck drift ratio $u_{\mathrm{rel}} / h_{\mathrm{s}}$ attained during and at the end of the seismic event, where $u_{\text {rel }}$ is the deck drift and $h_{\mathrm{s}}$ is the pier height. The main concern is then related to the evaluation of the period ratio $T_{\mathrm{eq}} / T_{0}$, where the increase of the eigen period of the system due to both soil-structure interaction effects and the development of irreversible strains into the soil should be properly considered.

In this paper, the simplified procedure proposed in [1] is firstly presented and the influence of soil plasticity and of properties of the seismic input are discussed. Then, a comparison is made of the period ratio $T_{\mathrm{eq}} / T_{0}$ provided by the $3 \mathrm{D}$ dynamic analyses with that evaluated through empirical relationships proposed in the literature, this allowing the simplified procedure to be adopted to get a reliable estimate of the seismic performance of bridge piers on caisson foundations.

\section{PROBLEM DEFINITION}

A schematic layout of the problem is depicted in Figure 1. The transversal section of a long-span and equally-spaced bridge deck is considered, so that the assumption of no interaction between two adjacent piers can be made. The cylindrical caisson foundation of height $H$ and diameter $D$ is embedded in a 5-m-thick gravelly sand layer underlain by a 55-m-thick layer of silty clay, this representing a typical alluvial deposit where caisson foundations may be preferred to pile foundations. The bedrock is at the depth $Z=60 \mathrm{~m}$, where the seismic input motion is applied in the $x$ direction in terms of horizontal acceleration time histories, this corresponding to the assumption of infinitely rigid bedrock. The water table is located at the interface between the sand and the clay $\left(z_{\mathrm{w}}=5 \mathrm{~m}\right)$ and a hydrostatic pore water pressure regime 


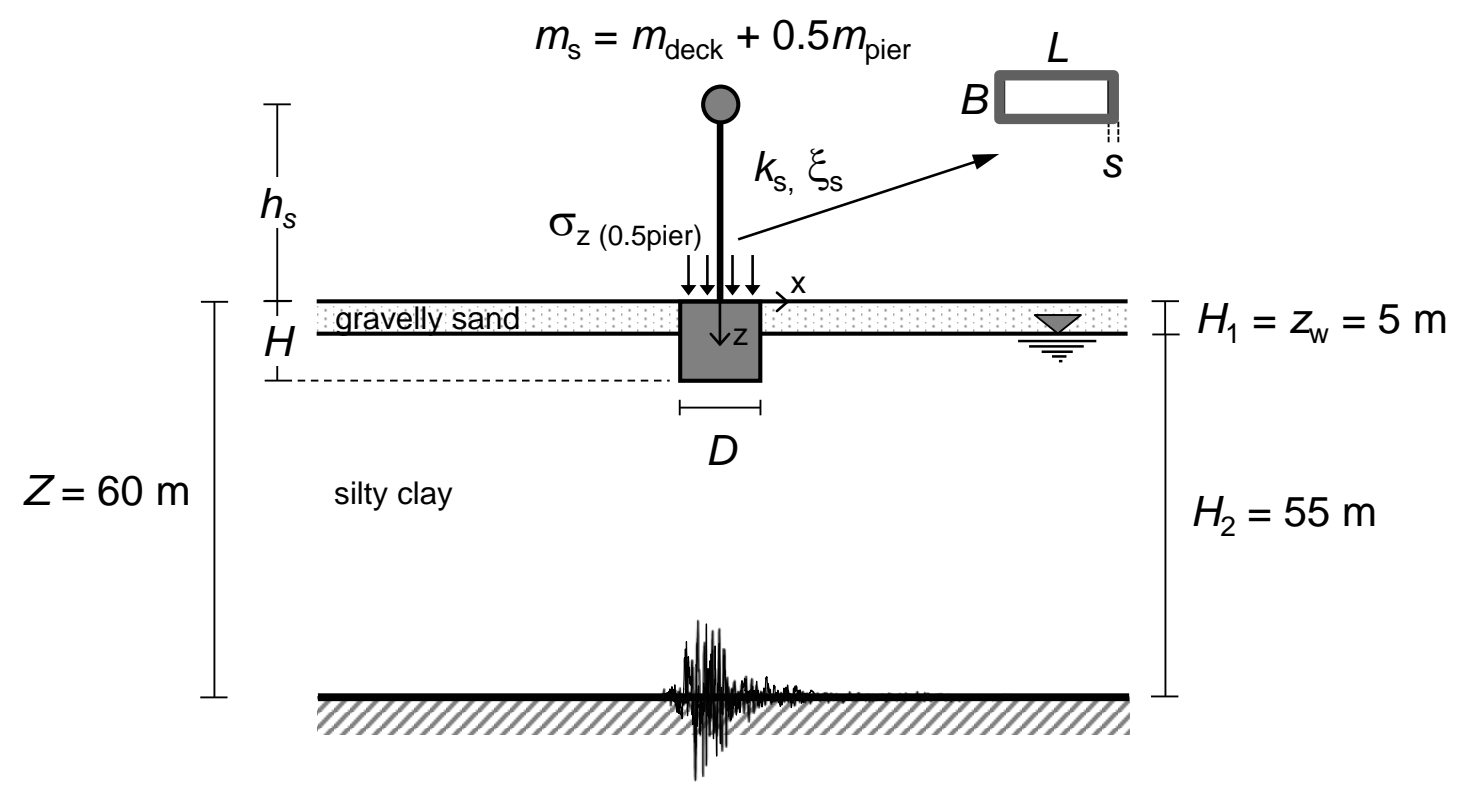

Figure 1: Schematic layout of the problem.

is assumed. The pier is assimilated to a linear viscous-elastic Single Degree of Freedom System (S.D.O.F.) characterized by a stiffness $k_{\mathrm{s}}$, here the flexural stiffness of the pier, a damping ratio $\xi_{\mathrm{s}}=5 \%$ and a lumped mass $m_{\mathrm{s}}=m_{\text {deck }}+0.5 \cdot m_{\text {pier, }}$, where $m_{\text {deck }}$ and $0.5 \cdot m_{\text {pier }}$ represent, respectively, the mass of a span (the part attributed to each of the piers in the adopted scheme) and the mass of the upper half of the pier. The mass of the lower half of the pier is applied to the top of the caisson via a uniform distribution of vertical stresses $\sigma_{\mathrm{z}(0.5 \mathrm{pier}) \text {. }}$

Mechanical properties of the foundation soils are listed in Table 1, where $\gamma$ is the unit weight, $c^{\prime}$ and $\varphi^{\prime}$ are the effective cohesion and the angle of shearing resistance, $O C R$ is the overconsolidation ratio and $k_{0}$ is the earth pressure coefficient at rest, the latter computed using following Mayne and Kulhawy [6]. The profile assumed for the small-strain shear modulus $G_{0}$ was obtained using the empirical relationships proposed by Hardin and Richart [7] for the gravelly sand and by Rampello et al. [8] for the silty clay.

In the parametric study, soil behaviour under cyclic loading was described through an elastic-plastic constitutive model with isotropic hardening and a Mohr-Coulomb failure criterion, the Hardening Soil with Small-Strain Stiffness (HS small) model [9]. The parameter adopted in the model are given in Table 1 , where $G_{0}{ }^{\text {ref }}$ and $m$ were calibrated to reproduce the abovementioned $G_{0}$ profile, while the shear strain $\gamma_{0.7}$ and the unloading-reloading modulus $E_{\mathrm{ur}}{ }^{\text {ref }}$ were obtained to best-fit the adopted shear modulus decay and damping increase curves, namely the ones proposed by Seed and Idriss [10] for the sand layer and the ones proposed by Vucetic and Dobry [11] for the clay layer. More details on the calibration of these parameters are given in $[12,13]$.

The high-intensity seismic inputs adopted in the non-linear dynamic analyses were grouped into two different sets, each characterized by three horizontal acceleration time histo-

\begin{tabular}{lcccccccccccc}
\hline Soil & $\begin{array}{c}\gamma \\
\left(\mathrm{kN} / \mathrm{m}^{3}\right)\end{array}$ & $\begin{array}{c}c^{\prime} \\
(\mathrm{kPa})\end{array}$ & $\begin{array}{c}\left.\varphi^{\prime}\right) \\
\left({ }^{\circ}\right)\end{array}$ & $\begin{array}{c}O C R \\
(-)\end{array}$ & $\begin{array}{c}k_{0} \\
(-)\end{array}$ & $\begin{array}{c}G_{0}{ }^{\mathrm{rel}} \\
(\mathrm{MPa})\end{array}$ & $\begin{array}{c}m \\
(-)\end{array}$ & $\begin{array}{c}\gamma_{0.7} \\
(\%)\end{array}$ & $\begin{array}{c}E_{\mathrm{ur}}{ }^{\mathrm{rel}} \\
(\mathrm{MPa})\end{array}$ & $\begin{array}{c}v_{\mathrm{ur}} \\
(-)\end{array}$ & $\begin{array}{c}E_{50}{ }^{\mathrm{rel}} \\
(\mathrm{MPa})\end{array}$ & $\begin{array}{c}E_{\text {oed }}{ }^{\mathrm{rer}} \\
(\mathrm{MPa})\end{array}$ \\
\hline Gravelly sand & 20 & 0 & 30 & 1.0 & 0.5 & 145.7 & 0.61 & 0.024 & 174.9 & 0.2 & 58.3 & 58.3 \\
Silty clay & 20 & 20 & 23 & $4.4 \div 1.5$ & $1.1 \div 0.7$ & 65.7 & 0.75 & 0.045 & 58.2 & 0.2 & 19.4 & 19.4 \\
\hline
\end{tabular}




\begin{tabular}{lccccc}
\hline Record & $F$ & $\begin{array}{c}a_{\max } \\
(-)\end{array}$ & $\begin{array}{c}I_{\mathrm{A}} \\
(\mathrm{m} / \mathrm{s})\end{array}$ & $\begin{array}{c}T_{\mathrm{m}} \\
(\mathrm{s})\end{array}$ & $\begin{array}{c}T_{\mathrm{D}} \\
(\mathrm{s})\end{array}$ \\
\hline Tolmezzo E-W & 1.00 & 0.316 & 1.17 & 0.50 & 5.220 \\
Assisi E-W & 2.00 & 0.332 & 1.12 & 0.24 & 4.295 \\
Adana E-W & 1.05 & 0.292 & 1.17 & 0.62 & 12.990 \\
\hline Colfiorito N-S & 2.00 & 0.676 & 2.79 & 0.51 & 5.115 \\
Nocera Umbra N-S & 1.00 & 0.502 & 2.87 & 0.21 & 4.640 \\
Dayhook N-S & 1.45 & 0.573 & 2.84 & 0.46 & 12.870 \\
\hline
\end{tabular}

Table 2: Main synthetic ground motion parameters of the scaled seismic input motions.

ries with the same intensity level. Specifically, the first set presents values of the Arias intensity $I_{\mathrm{A}}=1.12 \div 1.17 \mathrm{~m} / \mathrm{s}$, whereas the second is characterised by $I_{\mathrm{A}}=2.79 \div 2.87 \mathrm{~m} / \mathrm{s}$. Seismic inputs were amplified by factors $F$ ranging between 0.5 and 2, to match the desired Arias intensity (the one of Tolmezzo record for the first set and of Nocera Umbra for the second set) and a given site-specific spectrum. The main synthetic ground motion parameters of the selected seismic inputs are given in Table 2, where $a_{\max }$ is the peak horizontal acceleration, $T_{\mathrm{m}}$ is the mean period as defined in [14] and $T_{\mathrm{D}}$ is the significant duration as defined in [15]. In Table 2, the record on the second row of each set mainly differs from the one on the first row in terms of mean period $T_{\mathrm{m}}$, while the record on the third row differs for the significant duration $T_{\mathrm{D}}$. Figure 2 shows the relevant Fourier Amplitude (a-c) spectra and Arias intensity time histories (b-d).

In the parametric study, 14 different deck-pier-caisson-soil system were subjected to the 6 seismic inputs discussed above. Systems differ for the caisson diameter $(D=8$ and $12 \mathrm{~m})$ and slenderness ratio $(H / D=0.5,1$ and 2$)$, as well as for the pier height $\left(h_{\mathrm{s}}=15,30\right.$ and $\left.60 \mathrm{~m}\right)$. Values of stiffness $k_{\mathrm{s}}$ and masses $m_{\text {deck }}, m_{\text {pier }}$ and $m_{\mathrm{s}}$ are representative of span length ranging between 40 and $110 \mathrm{~m}$ (Tab. 3): they were obtained to return fixed values of the safety factor against bearing capacity under static and pseudo-static conditions, $F_{\mathrm{Sv}}=5.5$ and $F_{\mathrm{Se}}=0.7$, respectively. Initial stress conditions in the foundation soil are then equal for all the systems, this allowing a consistent comparison of their seismic performance. The value $F_{\mathrm{Se}}<1$ was

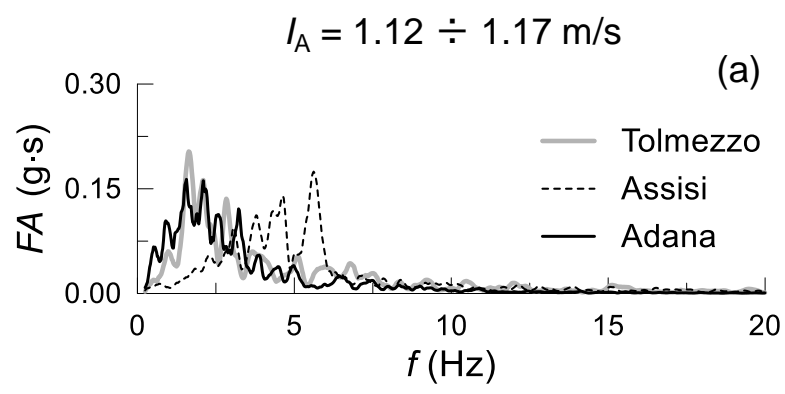

(a)

$$
I_{\mathrm{A}}=2.79 \div 2.87 \mathrm{~m} / \mathrm{s}
$$
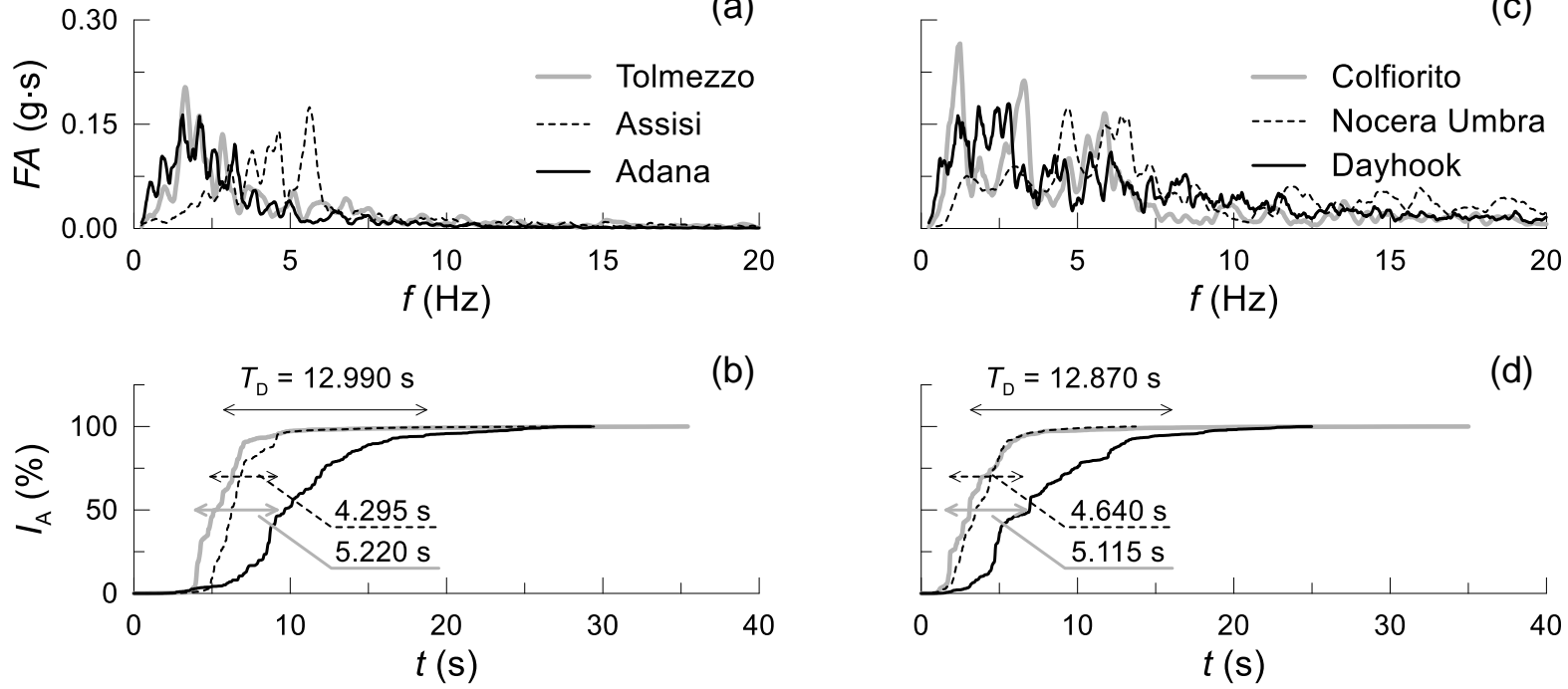

Figure 2: Selected seismic inputs: Fourier amplitude spectra (a-c) and time histories of Arias intensity (b-d). 


\begin{tabular}{|c|c|c|c|c|c|c|}
\hline $\begin{array}{c}D \\
(\mathrm{~m})\end{array}$ & $\begin{array}{c}/ D \\
(-)\end{array}$ & $\begin{array}{c}h_{\mathrm{s}} \\
(\mathrm{m})\end{array}$ & $\begin{array}{c}k_{\mathrm{s}} \\
(\mathrm{MN} / \mathrm{m})\end{array}$ & $\begin{array}{c}m_{\text {deck }} \\
(\mathrm{Mg})\end{array}$ & $\begin{array}{l}m_{\text {pier }} \\
(\mathrm{Mg})\end{array}$ & $\begin{array}{c}m_{\mathrm{s}} \\
(\mathrm{Mg})\end{array}$ \\
\hline \multirow{6}{*}{8} & 0.5 & 15 & 10.1 & 1278.0 & 196.7 & 1376.4 \\
\hline & \multirow{2}{*}{1} & 30 & 11.8 & 1500.3 & 217.2 & 1608.9 \\
\hline & & 60 & 6.2 & 698.6 & 1018.9 & 1208.1 \\
\hline & \multirow{3}{*}{2} & 15 & 102.4 & 2115.4 & 112.0 & 2171.4 \\
\hline & & 30 & 46.9 & 1804.8 & 422.6 & 2016.1 \\
\hline & & 60 & 20.8 & 1162.4 & 1065.0 & 1694.9 \\
\hline \multirow{8}{*}{12} & \multirow{3}{*}{0.5} & 15 & 106.4 & 3445.1 & 113.2 & 3501.7 \\
\hline & & 30 & 37.7 & 3173.5 & 384.8 & 3365.9 \\
\hline & & 60 & 19.8 & 2159.0 & 1399.3 & 2858.6 \\
\hline & \multirow{3}{*}{1} & 15 & 169.3 & 4160.5 & 134.6 & 4227.8 \\
\hline & & 30 & 78.7 & 3806.0 & 489.2 & 4050.6 \\
\hline & & 60 & 29.9 & 2841.1 & 1454.0 & 3568.1 \\
\hline & \multirow{2}{*}{2} & 30 & 411.2 & 4986.9 & 904.2 & 5439.0 \\
\hline & & 60 & 192.3 & 2374.3 & 3156.8 & 4132.7 \\
\hline
\end{tabular}

Table 3: Properties of the systems considered in the parametric study.

selected to promote the triggering of irreversible strains in the foundation soils during seismic shaking $[1,4]$. The coupled dynamic analyses were performed using the FE code PLAXIS 3D [16] where the numerical model shown in Figure 3 was implemented. The dynamic calculation stage was carried out after the drained activation of the caisson and of the superstructure. It is worth mentioning that the reduction of the stresses into foundation soils due to caisson excavation was indirectly considered by applying a volumetric contraction $\varepsilon_{\mathrm{v}}$ to the soil volume that would be filled by the concrete, thus the soil approaching active limit conditions at the soil-caisson contact. A consolidation analysis was then performed at the end of the dynamic calculation stage to allow the accumulated excess pore water pressures to vanish. A total of 51 dynamic analyses were performed, as the first set of seismic records was applied to all the 14 systems, while the second set was applied to the 9 systems characterised by $D=12 \mathrm{~m}$ and $h_{\mathrm{s}}=30 \mathrm{~m}$ only.

\section{ASSESSMENT OF THE SEISMIC PERFORMANCE}

The seismic performance of the systems was evaluated in terms of the deck drift ratio

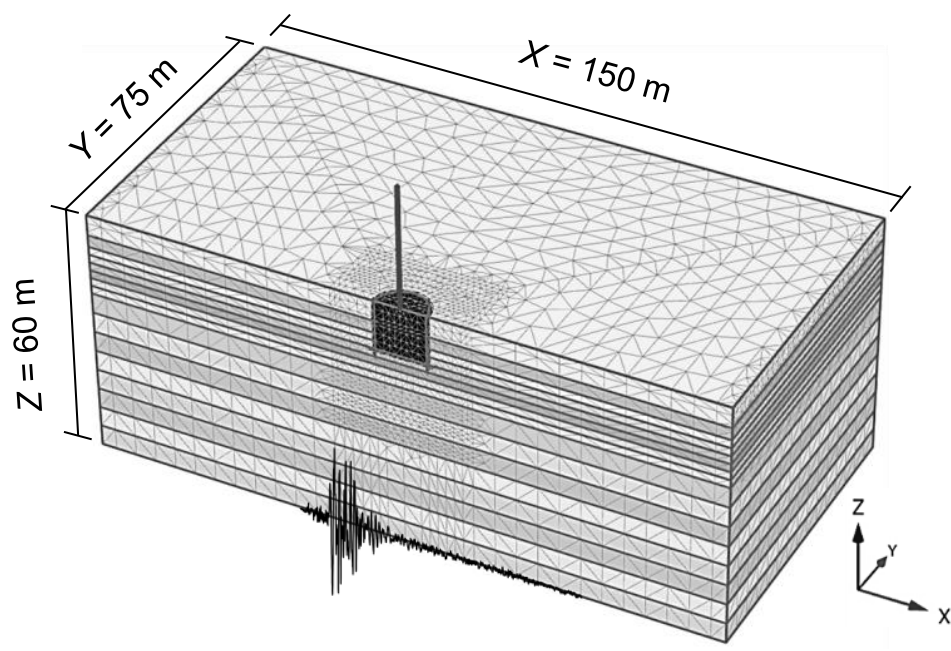

Figure 3: Numerical model adopted in the parametric study. 


\begin{tabular}{|llllll|}
\hline- Adana & $\bigcirc$ & Tolmezzo & $\bigcirc$ & Assisi \\
$\Delta$ & Dayhook & $\Delta$ & Colfiorito & $\triangle$ & Nocera Umbra \\
\hline
\end{tabular}
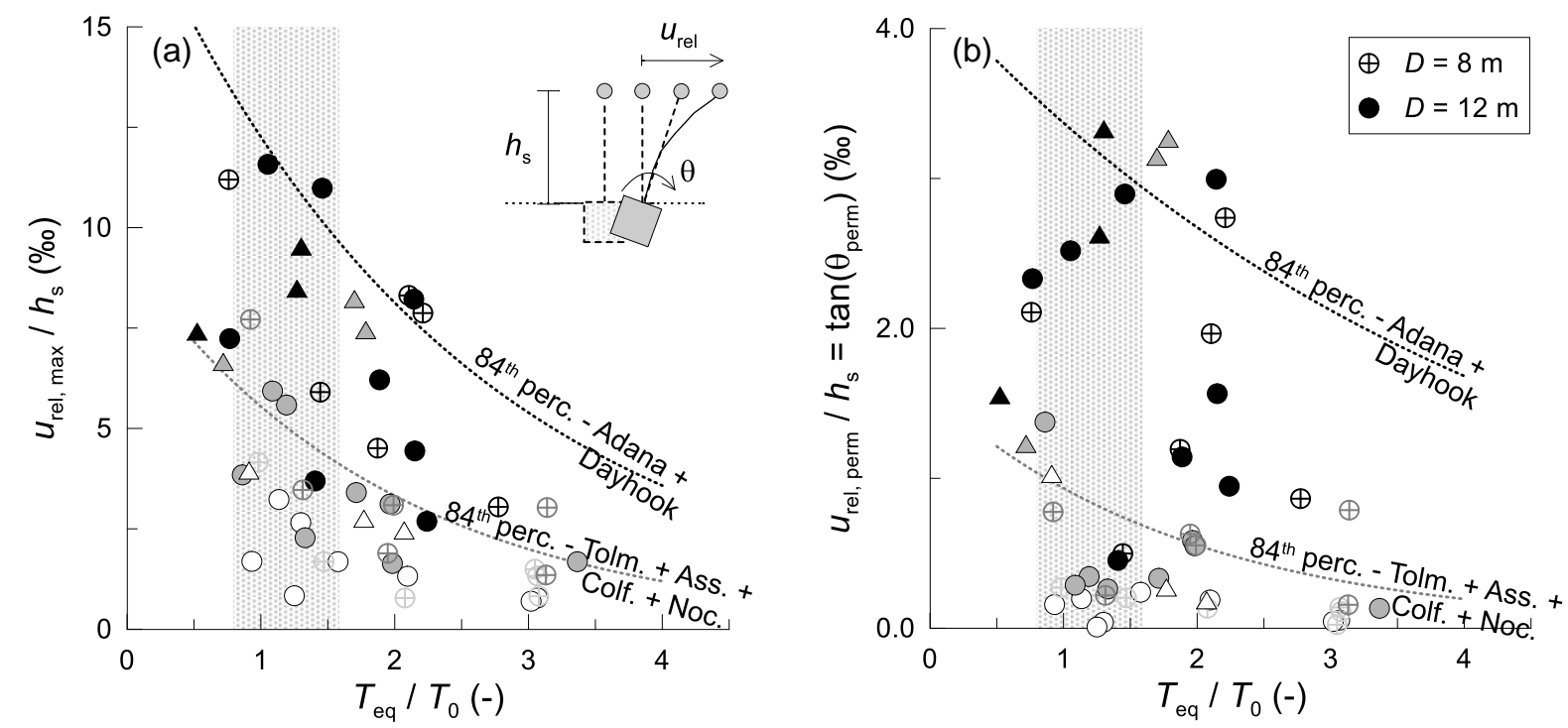

Figure 4: Maximum (a) and permanent (b) deck drift ratio against the period ratio.

$u_{\text {rel }} / h_{\mathrm{s}}$, defined as follows:

$$
\frac{u_{\text {rel }}}{h_{\mathrm{s}}}=\frac{u_{\text {deck }}}{h_{\mathrm{s}}}-\frac{u_{\text {caisson head }}}{h_{\mathrm{s}}}=\tan \theta+\frac{u_{\text {flex }}}{h_{\mathrm{s}}}
$$

where $\theta$ is the angle or rigid rotation of the caisson and $u_{\mathrm{flex}}$ is the flexural component of the horizontal displacement of the deck. The maximum and permanent values of $u_{\text {rel }} / h_{\mathrm{s}}$ computed during and at the end of the dynamic calculation phase are plotted in Figure 4a and 4b, respectively, against the period ratio $T_{\mathrm{eq}} / T_{0}$. The equivalent period $T_{\mathrm{eq}}$ was computed for each system from the ratio between the spectral acceleration at the level of the deck and of the top of the caisson $\left(R=S \mathrm{a}_{\text {deck }} / S \mathrm{a}_{\text {caisson head }}\right)$, both obtained in the 3D elastic-plastic dynamic analyses, while the fundamental period of the soil column $T_{0}$ was calculated through preliminary ground response analyses performed in free-field conditions using HS small. It is worth mentioning that both $T_{\mathrm{eq}}$ and $T_{0}$ account for the period increase due to soil plasticity.

Both the maximum and permanent values of the deck drift ratio show the highest values in the range $T_{\text {eq }} / T_{0} \approx 0.8 \div 2$, that is close to resonance conditions between the flexible base system and the soil column. Lower displacements (i.e. a better seismic performance) are observed for more flexible systems, that is for $T_{\mathrm{eq}} / T_{0} \geq 2$ [1]. With regard to seismic input properties, the records characterised by the longest significant duration $T_{\mathrm{D}}$ (Adana and Dayhook, black symbols) provide the highest values of the deck drift ratio, that is the worst seismic performance. On the contrary, the influence of Arias intensity $I_{\mathrm{A}}$ on the seismic performance is negligible for the cases at hand, as soil plasticity limits the inertial actions that could be transmitted to the superstructure. Finally, no remarkable influence of the caisson diameter $D$ is observed.

$84^{\text {th }}$ percentile upper-bound semi-empirical relationships were obtained from the results shown in Figure 4, by assuming a log-normal distribution of the deck drift ratio around its mean value and then best-fitting the computed drift ratios with an exponential expression: 


\begin{tabular}{lccc}
\hline Record & $u_{\text {rel }} / h_{\mathrm{s}}$ & $\begin{array}{c}A \\
(-)\end{array}$ & $\begin{array}{c}B_{84} \\
(\%)\end{array}$ \\
\hline \multirow{2}{*}{ Tolm. + Ass. + Colf. + Noc. } & Max. & 0.51 & 9.25 \\
& Perm. & 0.52 & 1.58 \\
\multirow{2}{*}{ Adana + Dayhook } & Max. & 0.41 & 18.48 \\
& Perm. & 0.23 & 4.25 \\
\hline
\end{tabular}

Table 4: Coefficients defining the $84^{\text {th }}$ percentile upper-bound deck drift ratios.

$$
\frac{u_{\mathrm{rel}}}{h_{\mathrm{s}}}=B_{84} \cdot \mathrm{e}^{-\mathrm{A} \cdot \mathrm{T}_{\mathrm{eq}} / \mathrm{T}_{0}}
$$

where $B_{84}$ is the deck drift ratio for $T_{\text {eq }} / T_{0}=0$ and $A$ is the slope of the curve in a semi-log plane. The coefficients defining the curves were obtained separately for the maximum and permanent values of $u_{\text {rel }} / h_{\mathrm{s}}$ and for high (Adana, Dayhook) and low (Tolmezzo, Assisi, Colfiorito, Nocera Umbra) significant durations $T_{\mathrm{D}}$ (Tab. 4). Upper-bound values of the intercept $B_{84}$ are of 1.58 to $18.48 \%$ with a mean value equal to $8.39 \%$, whereas values of the slope $A$ range between 0.23 and 0.52 with an average $A=0.42$. The upper-bound empirical relationships can be used for $T_{\mathrm{eq}} / T_{0} \geq 0.75$ to estimate the maximum expected deck drift ratio as a function of the dynamic properties of the flexible base system $\left(T_{\mathrm{eq}}\right)$, of the soil column $\left(T_{0}\right)$ and of the seismic input $\left(T_{\mathrm{D}}\right)$. The estimated displacements can also be used to perform a preliminary screen analysis, similarly to what is usually done for slopes [17]. The main concern for the evaluation of the deck drift ratio then regards the estimation of the period ratio $T_{\text {eq }} / T_{0}$. This key aspect is assessed in the next paragraph.

\section{ESTIMATION OF THE PERIOD RATIO}

In the proposed simplified procedure, it turned out that the period ratio $T_{\text {eq }} / T_{0}$ should be evaluated using some empirical and/or analytical relationships to overcome the issues related to time-consuming 3D non-linear dynamic analyses. To this end, here the possibility of using the empirical relationship proposed by Tsigginos et al. [18] for $T_{\mathrm{eq}}$ and an analytical formula for $T_{0}$ is assessed. Specifically, for the period $T_{\mathrm{eq}}$ it would be

$$
T_{\text {eq }}=T_{\mathrm{s}} \cdot\left[1+\left(\frac{2 \pi}{T_{\mathrm{s}}} \cdot \frac{h_{\mathrm{s}}}{V_{\mathrm{S}, \text { eq }}}\right)^{1.18}\left(\frac{m_{\mathrm{s}}}{m_{\text {caisson }}}\right)^{0.613}\left(2 \frac{h_{\mathrm{s}}}{D}\right)^{-0.5}\right]
$$

where $T_{\mathrm{s}}=2 \pi \sqrt{m_{\mathrm{s}} / k_{\mathrm{s}}}$ is the fixed-base period of the pier and $V_{\mathrm{S} \text {,eq }}$ is the equivalent shear wave velocity of the deposit, defined into the volume of soil interacting with the foundation ("zone of influence"). For the fundamental period of the soil column the simple formula for a homogeneous soil deposit, $T_{0}=4 Z / V_{\mathrm{S} \text {,eq }}$, is adopted.

The main concern related to these relationships relies on the fact that they are developed in the framework of linear viscous-elasticity, while the strong influence of soil plasticity on the seismic performance of the systems at hand has been recently clarified $[1,13]$. This key aspect can be embodied in the value of the equivalent shear wave velocity $V_{\mathrm{S} \text {,eq }}$ adopted in calculations. Therefore, a ground response analysis analysis should be performed with the linearequivalent method [19]. An example is given in Figure 5 for the input of Tolmezzo, where $\gamma_{\text {eff }}=0.65 \cdot \gamma_{\max }$ is the shear strain in a constant-amplitude cycle, equivalent to the peak value 

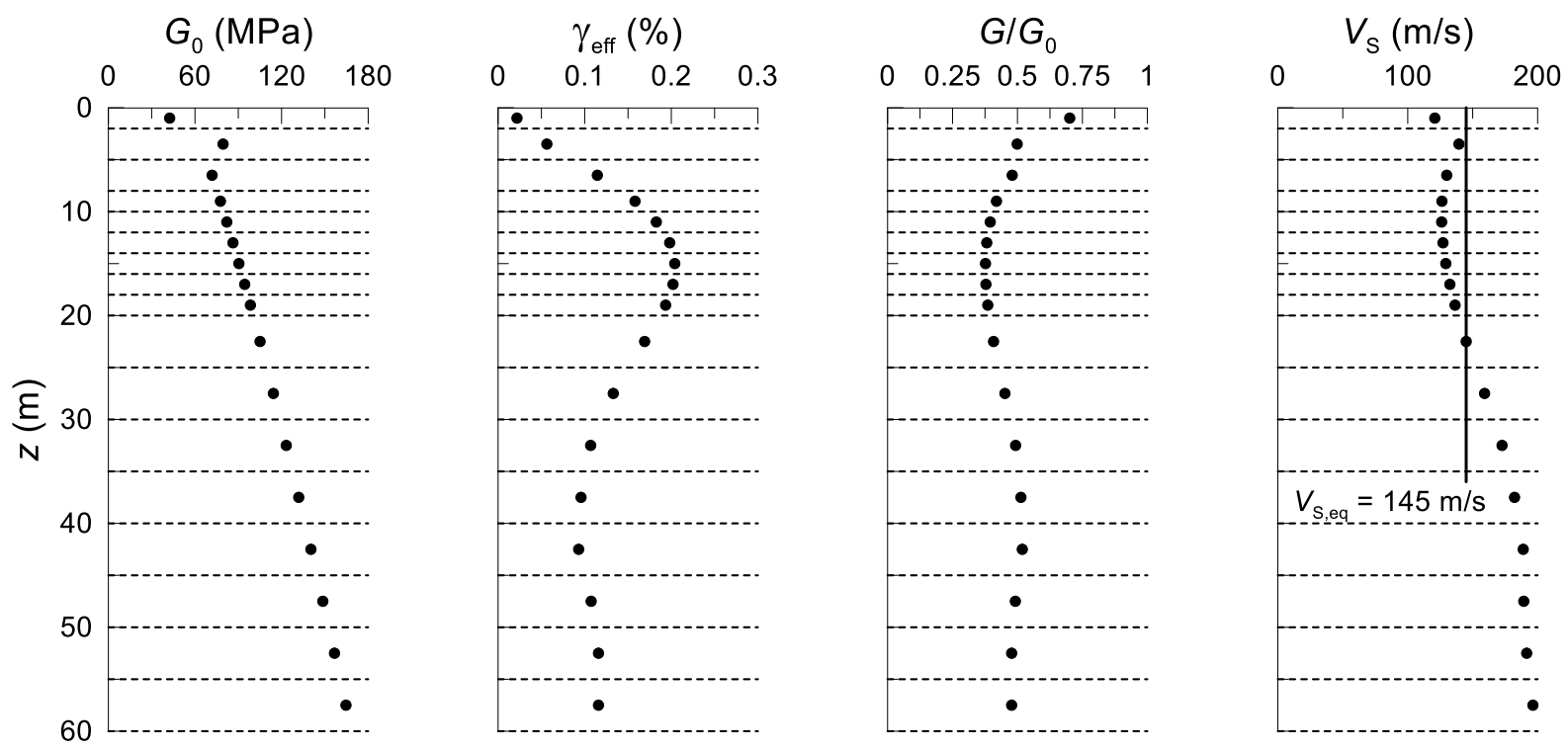

Figure 5: Computation of the equivalent operative shear wave velocity $V_{\mathrm{S} \text {,eq }}$ from the results of a site response analysis performed in free-field conditions with the linear-equivalent method (Tolmezzo record, caisson with $D=H=12 \mathrm{~m})$.

$\gamma_{\max }, G / G_{0}$ is the shear modulus decay caused by $\gamma_{\mathrm{eff}}$ and $V_{\mathrm{S}}=\sqrt{G / \rho}$ is the corresponding shear wave velocity $\left(\rho=2.04 \mathrm{Mg} / \mathrm{m}^{3}\right.$ is soil density). Assuming an "influence zone" down to a depth $z_{\max }=H+2 D$, the equivalent shear wave velocity can be computed as

$$
V_{\mathrm{S}, \mathrm{eq}}=\frac{\sum_{\mathrm{i}=1}^{\mathrm{n}} h_{\mathrm{i}}}{\sum_{\mathrm{i}=1}^{\mathrm{n}} \frac{h_{\mathrm{i}}}{V_{\mathrm{S}, \mathrm{i}}}}=\frac{H+2 D}{\sum_{\mathrm{i}=1}^{\mathrm{n}} \frac{h_{\mathrm{i}}}{V_{\mathrm{S}, \mathrm{i}}}}
$$

where $h_{\mathrm{i}}$ is the thickness of the $i^{\text {th }}$ stratum discretising the soil column and $n$ is the number of strata. For the caisson characterised by a diameter $D=H=12 \mathrm{~m}$, a depth $z_{\max }=36 \mathrm{~m}$ and a shear wave velocity $V_{\mathrm{S} \text {,eq }}=145 \mathrm{~m} / \mathrm{s}$ are obtained. The assumption of the maximum depth being $z_{\max }=H+2 D$ was compared with numerical results, obtaining a good agreement [1]. The shear wave velocity computed for all the 51 different combinations of systems and seismic inputs are listed in Table 5, where $V_{\mathrm{S} 0 \text {,eq }}$ is the "small-strain" equivalent shear wave velocity, not dependent on the adopted seismic input.

\begin{tabular}{|c|c|c|c|c|c|c|c|c|}
\hline \multirow{2}{*}{$\begin{array}{l}D \\
(\mathrm{~m})\end{array}$} & \multirow{2}{*}{$\begin{array}{l}H / D \\
(-)\end{array}$} & \multirow{2}{*}{$\begin{array}{l}V_{\mathrm{S} 0, \mathrm{eq}} \\
(\mathrm{m} / \mathrm{s})\end{array}$} & \multicolumn{6}{|c|}{$\begin{array}{c}V_{\mathrm{S}, \mathrm{eq}} \\
(\mathrm{m} / \mathrm{s})\end{array}$} \\
\hline & & & Tolmezzo & Assisi & Adana & Colfiorito & Nocera & Dayhook \\
\hline \multirow{3}{*}{8} & 0.5 & 192.9 & 130.2 & 148.2 & 130.4 & 125.3 & 136.6 & 121.7 \\
\hline & 1 & 197.8 & 132.9 & 152.6 & 131.9 & 126.4 & 138.6 & 124.5 \\
\hline & 2 & 206.4 & 140.9 & 162.3 & 137.3 & 130.4 & 144.6 & 130.8 \\
\hline \multirow{3}{*}{12} & 0.5 & 204.4 & 136.7 & 157.5 & 134.3 & 128.3 & 141.4 & 127.9 \\
\hline & 1 & 210.4 & 145.0 & 166.6 & 140.3 & 132.6 & 147.8 & 133.3 \\
\hline & 2 & 221.2 & 152.1 & 175.2 & 145.3 & 137.1 & 153.8 & 137.9 \\
\hline
\end{tabular}




\begin{tabular}{|llllll|}
\hline - Adana & Tolmezzo & $\bigcirc$ & Assisi \\
$\triangle$ & Dayhook & \multicolumn{1}{l}{ Colfiorito } & $\triangle$ & Nocera Umbra \\
\hline
\end{tabular}
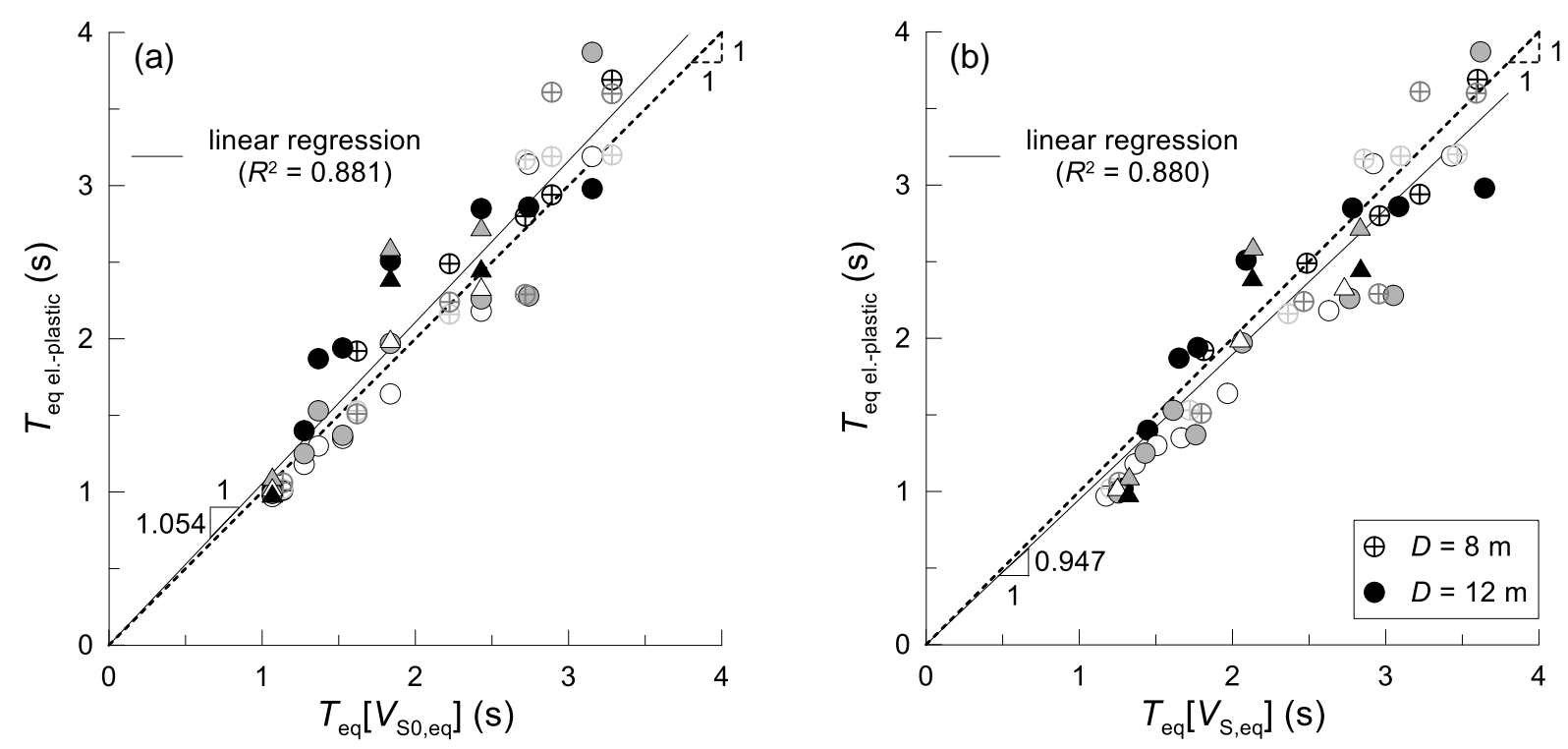

Figure 6: Comparison between the fundamental period of the system obtained from the numerical elastic-plastic analyses and the one computed using the empirical relationship by Tsigginos et al. [18] with: (a) $V_{\mathrm{S} 0 \text {,eq }}$; (b) $V_{\mathrm{S} \text {,eq }}$.

The equivalent shear wave velocities were then used to calculate the equivalent period $T_{\text {eq }}$ with eq. (3), thus obtaining the results shown in Figure 6. These values of $T_{\text {eq }}$ were computed using $V_{\text {S0,eq }}\left(\right.$ Fig. 6a) and $V_{\text {S,eq }}$ (Fig. 6b): both were then compared to the equivalent period computed from the $3 \mathrm{D}$ elastic-plastic analyses, $T_{\text {eq el.-plastic. The numerical and empirical values }}$ of $T_{\text {eq }}$ are in good agreement for both $T_{\text {eq }}\left[V_{\mathrm{S} 0 \text {,eq }}\right]$ and $T_{\text {eq }}\left[V_{\mathrm{S} \text {,eq }}\right]$, with a slight underestimation of the equivalent period using $V_{\mathrm{S} 0 \text {,eq }}$ and a slight overestimation using $V_{\mathrm{S} \text {,eq. }}$ Indeed, linear regressions returned values of the angular coefficient very close to unity, namely 1.054 and 0.947 for $V_{\mathrm{S} 0 \text {,eq }}$ and $V_{\mathrm{S} \text {,eq }}$, respectively. Also, high coefficients of determination were obtained in both cases, with the same value $R^{2}=0.88$.

From the above results it could be concluded that it is not necessary to perform preliminary ground response analyses with the linear-equivalent method to evaluate $V_{\mathrm{s}, \mathrm{eq}}$ (see Fig. 5). However, the fundamental period of the soil column in free-field condition, $T_{0}$, is to be computed to use eq. (2). Figure 7 shows the remarkable differences obtained if the "small-strain" equivalent shear wave velocity $V_{\mathrm{S} 0 \text {,eq }}$ is used. Indeed, an angular coefficient further from unity is calculated when finding the linear regression, equal to 0.914 , with a greater dispersion $\left(R^{2}=0.83\right)$. Conversely, using $V_{\mathrm{S} \text {,eq }}$ from the results of the ground response analyses provides an angular coefficient of the linear regression equal to 1.053 , again very close to unity, with a lower scatter of the data $\left(R^{2}=0.87\right)$. Therefore, adopting the equivalent shear wave velocity $V_{\mathrm{S} \text {,eq }}$ from ground response analyses is strongly recommended.

\section{CONCLUSIONS}

The evaluation of the seismic performance of bridge piers founded on cylindrical caissons would require, in principle, expensive and time-consuming 3D non-linear dynamic analyses performed with numerical methods. However, this approach cannot be taken as a design reference tool. Therefore, Gaudio and Rampello [1] recently provided upper-bound relationships to get an estimate of the maximum and permanent values of the deck drift ratio $u_{\mathrm{rel}} / h_{\mathrm{s}}$ as func- 


\begin{tabular}{|llllll|}
\hline- Adana & Tolmezzo & $\bigcirc$ & Assisi \\
$\triangle$ & Dayhook & $\triangle$ & Colfiorito & $\triangle$ & Nocera Umbra \\
\hline
\end{tabular}
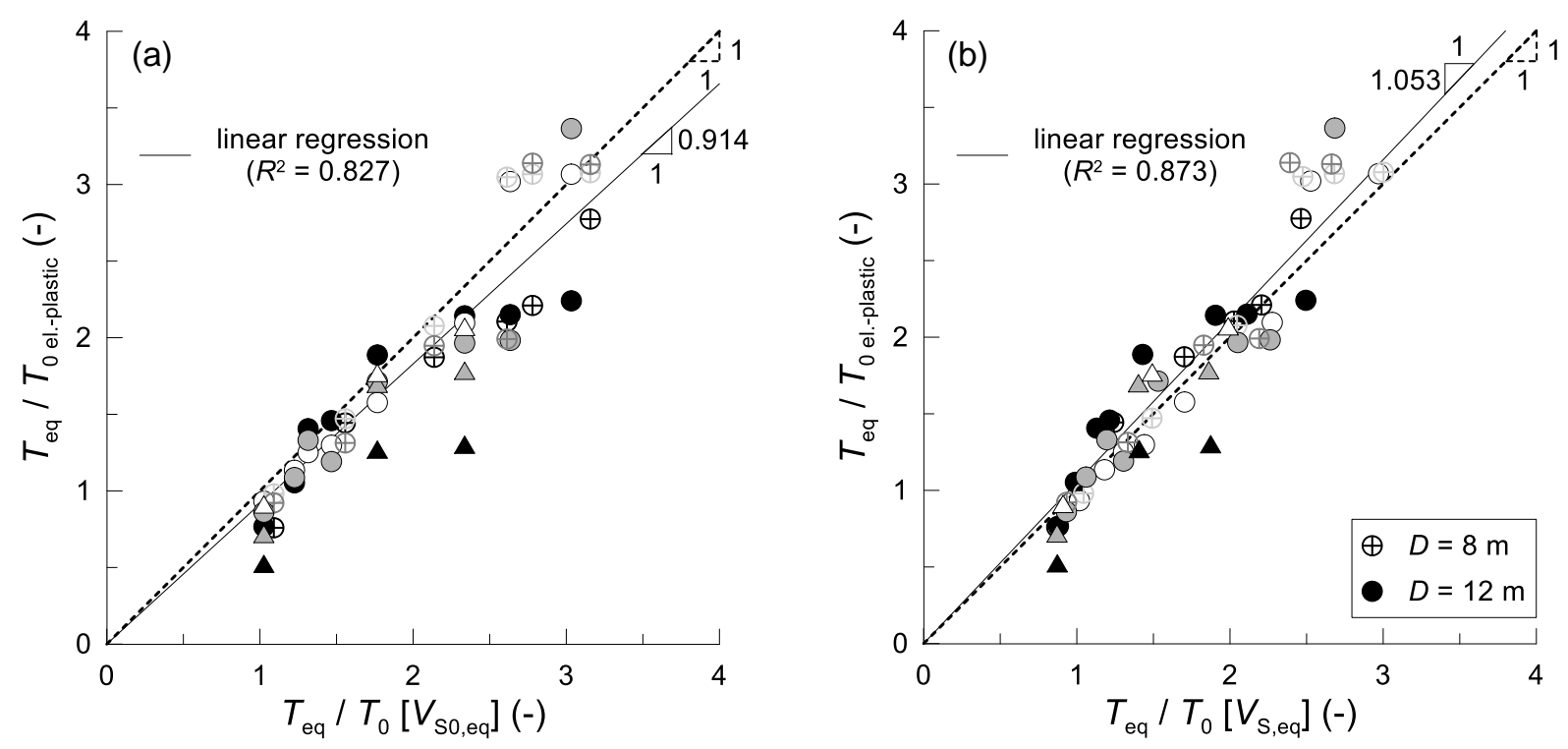

Figure 7: Comparison between the period ratio obtained from the numerical elastic-plastic analyses and the one computed using the empirical and analytical relationship for $T_{\mathrm{eq}}$ and $T_{0}$, respectively, with: (a) $V_{\mathrm{S} 0 \text {,eq }}$; (b) $V_{\mathrm{S} \text {,eq }}$.

tions of the period ratio $T_{\mathrm{eq}} / T_{0}$ and of the significant duration of the seismic input $T_{\mathrm{D}}$. It is shown that empirical and analytical relationships available in the literature can be profitably adopted for the evaluation of the period ratio $T_{\mathrm{eq}} / T_{0}$, provided that preliminary ground response analyses are performed with the linear equivalent method, thus obtaining a fair estimation of the reduction of the shear wave velocity due to the non-linear soil behaviour triggered during strong ground motions. Once $T_{\mathrm{eq}} / T_{0}$ is evaluated, a preliminary estimate of the maximum or permanent deck drift ratio can be obtained using the proposed empirical relationships.

\section{REFERENCES}

[1] D. Gaudio, S. Rampello, The influence of soil plasticity on the seismic performance of bridge piers on caisson foundations. Soil Dynamics and Earthquake Engineering, 118, 120-133, 2019. DOI: 10.1016/j.soildyn.2018.12.007

[2] L. Callisto, S. Rampello, G.M.B. Viggiani, Soil-structure interaction for the seismic design of the Messina Strait Bridge. Soil Dynamics and Earthquake Engineering, 52, 103$115,2013$.

[3] S. Rampello, L. Callisto, G.M.B. Viggiani, Predicting the seismic behaviour of the foundations of the Messina Strait Bridge. Bulletin of Earthquake Engineering, 12 (3), 1201-1219, 2013.

[4] A. Zafeirakos, N. Gerolymos, On the seismic response of under-designed caisson foundations. Bulletin of Earthquake Engineering, 11 (5), 1337-1372, 2013.

[5] A. Zafeirakos, N. Gerolymos, Towards a seismic capacity design of caisson foundations supporting bridge piers. Soil Dynamics and Earthquake Engineering, 67, 179-197, 2014. 
[6] P.W. Mayne, F.H. Kulhawy, K0 - OCR relationships in soil. Journal of the Geotechnical Engineering Division, ASCE, 108 (GT6) 851-872, 1982.

[7] B.O. Hardin, F.E. Richart, Elastic wave velocities in granular soils. Journal of the Soil Mechanics and Foundation Division, ASCE, 89 (SM1) 33-65, 1963.

[8] S. Rampello, F. Silvestri, G. Viggiani, The dependence of G0 on stress state and history in cohesive soils. Balkema ed. $1^{\text {st }}$ International Symposium on Pre-Failure Deformation Characteristics of Geomaterials - Measurements and Applications, 2, 1155-1160, Sapporo, Japan, 1994.

[9] T. Benz, P.A. Vermeer, R. Schwab, A small-strain overlay model. International Journal for Numerical and Analytical Methods in Geomechanics, 33 (1), 25-44, 2009.

[10] H.B. Seed, I.M. Idriss, Soil moduli and damping factors for dynamic response analyses, Report No. EERC 70-10. Earthquake Engineering Research Centre, University of California, Berkeley, California, 1970.

[11] M. Vucetic, R. Dobry, Effect of soil plasticity on cyclic response. Journal of Geotechnical Engineering, 117 (1), 89-107, 1991.

[12] D. Gaudio, S. Rampello, Dynamic soil-structure interaction of bridge-pier caisson foundations. Geotechnical engineering in multidisciplinary research: from microscale to regional scale CNRIG2016. VI Italian Conf. of Researchers in Geotechnical Engineering, Procedia Engineering, 158, 146-151, Bologna, Italy, 2016. DOI: 10.10167j.proeng.2016.08.420

[13] D. Gaudio, S. Rampello, The role of soil constitutive modelling on the assessment of seismic performance of caisson foundations. $7^{\mathrm{TH}}$ International Conference on Earthquake Geotechnical Engineering, 7ICEGE, Rome, Italy, June 17-20, 2019 (in press).

[14] E.M. Rathje, N. Abrahamson, J.D. Bray, Simplified frequency content estimates of earthquake ground motions. Journal of Geotechnical and Geoenvironmental Engineering, ASCE, 124 (2), 150-159, 1998.

[15] M.D. Trifunac, A.G. Brady, A study on the duration of strong earthquake ground motion. Bulletin of the Seismological Society of America, 65 (3), 581-626, 1975.

[16] R.B.J. Brinkgreve, E. Engine, W.M. Swolfs, PLAXIS 3D. Reference Manual, 2013.

[17] J.P. Stewart, T.F. Blake, R.A. Hollingsworth, A screen analysis procedure for seismic slope stability. Earthquake Spectra, 19 (2), 697-712, 2003.

[18] C. Tsigginos, N. Gerolymos, D. Assimaki, G. Gazetas, Seismic response of bridge pier on rigid caisson in soil stratum. Earthquake Engineering and Engineering Vibration, 7 (1), 33-44, 2008.

[19] I.M. Idriss, H.B. Seed, Response of horizontal soil layers during earthquakes. Journal of the Soil Mechanic and Foundations Division, ASCE, SM4, 1003-1031, 1968. 